work as that recently carried out by Eggert and Delevoryas, adopting an ontogenetic approach, has indicated how important a factor variation within the individual may be in some kinds of fossil plants.

Crookall's work may stand in the best tradition of nineteenth century palaeobotany; it does little to stimulate a modern approach, unless by drawing attention to the weaknesses of the traditional outlook.

K. L. Alvin

\section{SYMMETRICAL CREATURES}

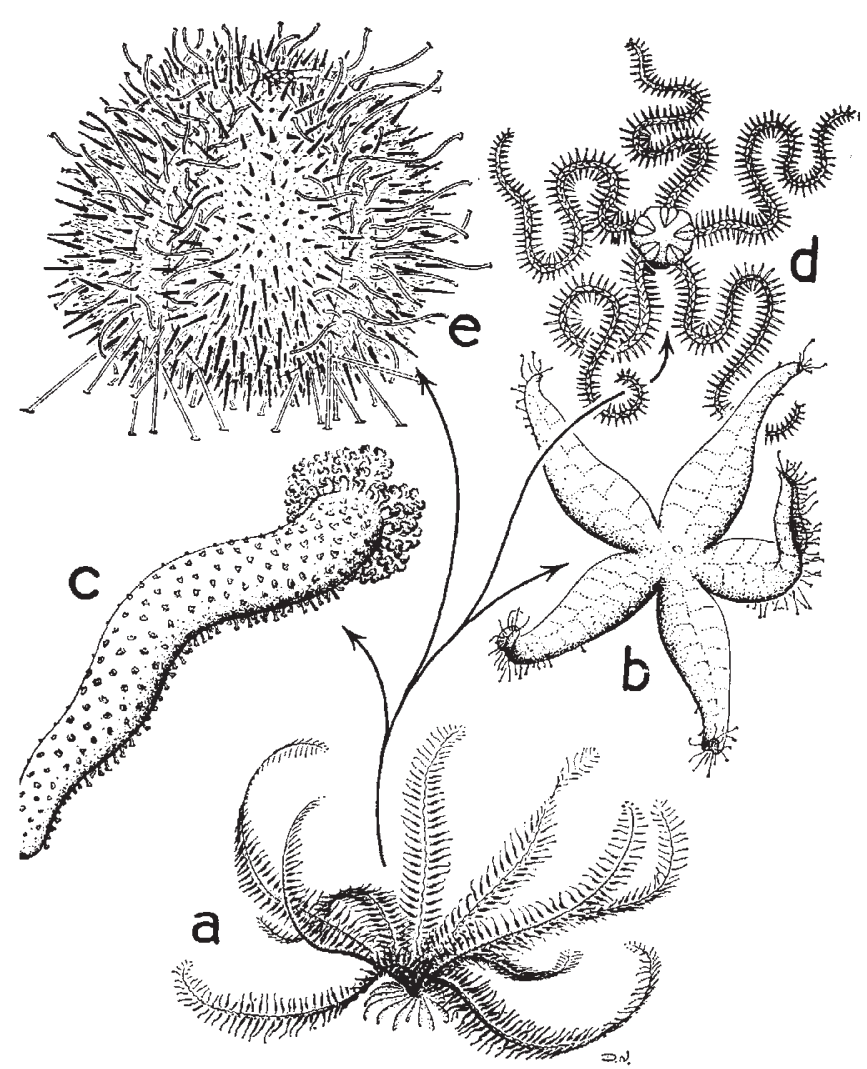

Professor D. Nichols's introduction to the Echinoderms has been published in a new revised edition (Hutchinson: London, October 1969 (4th edition), 12s paper; 28s boards). He has changed the taxonomic framework of the book in the light of new knowledge about fossil echinoderms, and he has also altered sections on, for example, the water vascular system and on the relationships of the various groups. Echinoderms living today are grouped into five classes as represented in the figure: (a) Crinoidea, the sea lilies and feather stars, the most primitive living class; (b) Asteroidea, the starfishes; (c) Holothuroidea, the sea cucumbers; (d) Ophiuroidea, the brittle stars and basket stars; and (e) Echinoidea, the sea urchins, sand dollars and heart urchins. There are also several classes which are now completely extinct.

\section{IMMORTAL UNDER THE KNIFE}

\section{Planarian Regeneration}

By H. V. Brøndsted. (International Series of Monographs in Pure and Applied Biology, Zoology Division, Vol. 42.) Pp. viii $+276+20$ plates. (Pergamon: Oxford, London and New York, October 1969.) 100s; $\$ 13.50$.

DALXELL's arresting aphorism no doubt has assured immortality also for itself and for the study of planarian regeneration. A review of this intriguing field therefore is never untimely, and in life-long devotion to the subject few are now more qualified to write one than Professor Brondsted. This is evident from the list of some 800 references, the historical introduction, the many aspects considered and the many incisive experiments by the author himself.

After the general and historical introductions, the book goes on to morphogenetic and then histological aspects of regeneration, the actions of external agents, biochemical and biophysical approaches and finally genetic aspects. Interspersed are chapters on heteromorphoses and reindividuation and on asexual reproduction. The rationale of this and of some other foatures of the arrangement is not very clear and fails to provide a really systematic development. Even the author's own ficld, morphogenetic and histolngical, seems to be more a set of chapters than a compelling sequence. In the final chapters a student may feel rather adrift. This is only partly because of the present paucity of knowledge: the author sometimes fails to do justice to the interpretation of available results. Some of these, for instance, on protein and nucleic acid synthesis (page 191) promise new approaches to the whole subject. The final "attempt at a synthesis" is more justifiably disappointing.

Child's theories on gradient-phenomena in regeneration naturally are discussed at length, but would bear a little more dissoction into their components, accoptable and unacceptable. In substituting his "time-graded regencration-field" the author himself runs the risk of seduction by cuphony. This is reflected in cryptic references to the importance of time and in an acceptance of such imprecise terms as "head frequency".

In the newer polemic concerning "neoblasts", Brondsted takes the majority view. Ho also goes on to assume almost every function for this type of cell, except those which, from the evidence in other phyla, might be considered very plausible for vagrant colls - defence, demolition and local nutrition.

The text is abundantly illustrated, intentionally with new figures. Unfortunately, many have no caption and some of these (for example, 17, 25, 96, 126, 143-6) are not fully explained in the text. The author's admirable command of English only occasionally fails him in a critical context. There are some minor printer's and other errors, including a few incompleto references. This book is primarily for teachers and research workers.

\section{A. E. NeEDHaM}

\section{TECHNIQUES FOR DISSECTION}

\section{Practical Invertebrate Zoology}

A Laboratory Manual for the Study of the Major (Aroups of Invertebrates, excluding Protochordates. By F. E. G. Cox, R. Phillips Dales, J. Green, J. E. Morton, D. Nichols and D. Wakelin. (Biology Series.) Pp. xii +356 . (Sidgwick and Jackson: London, 1969.) $25 s$.

This book is to be welcomed because almost twenty years have elapsed since the publication of a comprehensive text on practical invertebrate zoology. Six teachers, each specially interested in one or more invertebrate groups, have collaborated to produce this book under the editorship of Dr R. Phillips Dales. Their aim was to provide sufficiont information to introduce students to the many different kinds of living invertebrates and to draw attention to features of special interest. While the different, authors have been allowed to devolop their personal enthusiasms, a uniformity of presentation of the sections concerning each phylum leads to a manual which is easy to use and has a coherent approach. Each major phylum has sections on the particular techniques appropriate to its study, classification, with brief diagnostic features, and anatomy. Features which are most welcome are the diagrams, all being original drawings, the indication of sources of further information, summarized in a well 